\title{
Assessment of Oral and Dental Health Status in Children with Cerebral Palsy: An Exploratory Study
}

\author{
Nabila A Sedky
}

\section{ABSTRACT}

Objectives: Evaluating oral and dental health status in Egyptian children with cerebral palsy $(\mathrm{CP})$ in relation to gross motor skills and types of CP.

Materials and methods: Cross-sectional study was conducted at el-Shatby Hospital for Children, Alexandria, Egypt. Oral examination for 62 children with $\mathrm{CP}$ between the age range 3 and 12 years was performed, and decayed, missing, and filled permanent teeth (DMFT)/decayed and filled primary teeth (dft), simplified oral hygiene index (OHI-S), and modified gingival index (MGI) were charted. Maxillofacial defects, dental problems, and drooling of saliva were assessed. Children's CP type, motor milestone, and gross motor skills were determined. All statistical analyses were carried out at $p<0.05$ and 0.01 .

Results: About $84.0 \%$ of children had spastic quadriplegia, 41.9\% were sit-supported, $32.3 \%$ had level IV Gross Motor Function Classification System (GMFCS), 29.0\% had level V no maxillofacial defects, $14.5 \%$ had dentin exposure greater than one-third of the surface, and $22.6 \%$ had frequent/severe drooling saliva. Caries prevalence comprised 54.8\%, 53.2\% had poor oral hygiene (OHI-S), and $43.6 \%$ had severe gingival inflammation (MGI). The first best predictor variable for $\mathrm{dft}$ was "motor milestone" The GMFCS (levels IV and V) was the first best predictor variable for DMFT, OHI-S, and MGI.

Conclusion: The majority of children had dental caries, poor oral hygiene, and severe gingival inflammation. Children who were sit-supported, had no neck support, and stand-supported were suffering from dental caries (dft) more than children who were sitting and walking alone. Children with levels IV/V GMFCS were prone to have dental caries (DMFT), susceptible to suffer from bad oral hygiene, and older children experiencing severe gingivitis more than younger ones.

Keywords: Cerebral palsy, Dyskinetic, Monoplegia.

How to cite this article: Sedky NA. Assessment of Oral and Dental Health Status in Children with Cerebral Palsy: An Exploratory Study. J Contemp Dent 2017;7(1):1-11.

Source of support: Nil

Conflict of interest: None

\section{Associate Professor}

Department of Community Dentistry and Oral Epidemiology College of Dentistry, Qassim University, Buraidah, Qassim Kingdom of Saudi Arabia

Corresponding Author: Nabila A Sedky, Associate Professor Department of Community Dentistry and Oral Epidemiology College of Dentistry, Qassim University, Buraidah, Qassim Kingdom of Saudi Arabia, Phone: +966538127210 , e-mail: nasedky@yahoo.com

\section{INTRODUCTION}

Cerebral palsy $(\mathrm{CP})$ is presently viewed as the principal crippling condition in childhood and is one of the chief neurological disorders. ${ }^{1}$

Population-based evaluations of CP prevalence range from 1.5 to more than 4 per 1,000 live births or per children of a distinct age category. ${ }^{2-7}$ Cerebral palsy is a disorder caused by injury to the brain, commonly happening before, during, or shortly after birth. "Cerebral" represents the brain and "palsy" implies a disturbance of movement or posture. Cerebral palsy is a central nervous system disorder of movement, coordination, and posture, revealing a nonprogressive deformity or insult to the immature brain. ${ }^{8}$ Cerebral palsy is neither progressive nor transmissible. Moreover, it is not curable, despite the fact that learning, treatment, and applied technology can assist people with $\mathrm{CP}$ run humane and dignified lives. ${ }^{9}$

Cerebral palsy is classified according to the type of body movement and posture problem into spastic (pyramidal), nonspastic (extrapyramidal), and mixed CP. Spastic CP is the most common type. A person with spastic $\mathrm{CP}$ develops tight muscles in some parts of the body that are unable to relax. Affected joints become stiff and hard to move. Usually, a person has problems in movements control, poor coordination, and balance, as well as talking and eating with difficulty. There are four types of spastic $\mathrm{CP}$, categorized according to how many limbs are affected. Monoplegia; hemiplegia or diplegia, which are the most common types of spastic $\mathrm{CP}$; triplegia; and quadriplegia, in which both arms and both legs are affected additionally, commonly the trunk and muscles that control the mouth, tongue, and windpipe are affected too. This leads to difficulty in eating and talking. Babies with spastic quadriplegia may have problems in sucking and swallowing, a weak or shrill cry, a very relaxed and floppy or a very stiff body; when held they may arch their backs and extend their arms and legs, be irritable when awake, sleep a lot, or show little interest in what is going on around them. The other type of $\mathrm{CP}$ is the nonspastic forms that include dyskinetic CP (subdivided into athetoid and dystonic forms) and ataxic CP. Dyskinetic CP is associated with muscle tone that fluctuates between being loose and tight. Athetoid (hyperkinetic) $\mathrm{CP}$ characteristics include relaxed and limp muscles during sleep, with some involuntary jerking (chorea) or writhing 
(athetosis). If the face and mouth muscles are affected, problems may develop related to unusual facial expressions, drooling, speaking, and choking when sucking, drinking, and eating. Ataxic $\mathrm{CP}$ is the rarest type and involves the entire body. Abnormal body movements affect the trunk, hands, arms, and legs. Ataxic $\mathrm{CP}$ causes problems with balance, exact movements, coordination, and hand control. The third type is mixed $\mathrm{CP}$ in which some children have symptoms of more than one type of $\mathrm{CP}$. Additionally, total body $\mathrm{CP}$ is the type that affects the entire body to some degree. Complications of $\mathrm{CP}$ and other medical problems are more likely to develop when the entire body is involved rather than isolated parts. Total body CP may include any of the types of $\mathrm{CP}$, spastic quadriplegic, dyskinetic, or ataxic..$^{10-12}$

Studies have demonstrated that increased severity of the neurological damage in children with $\mathrm{CP}$ resulted in higher risk of oral diseases. ${ }^{13,14}$ Children with $\mathrm{CP}$ regularly have physical, coordinative, sensory, intelligence, communication, and cognitive problems in implementing, detecting, and retaining self-care activities of daily living (ADLs), such as walking, showering, wearing clothes, teeth brushing, eating, talking, and ambulating. ${ }^{15,16}$ These challenges extremely influence their ADLs and lead to a deteriorated oral health condition in the form of high caries rate, decreased number and rate of restored teeth and/or poor quality restorations, as well as intense periodontal inflammation. Consequently, children with $\mathrm{CP}$ frequently necessitate intensive dental care. ${ }^{17-23}$ A previous study discovered that the decayed, missing and filled permanent surfaces (DMFS) of children with $C P$ was 12.86 , which was significantly higher than that of normal children that was 2.87; likewise, the dental plaque index was higher in children with $\mathrm{CP}^{24} \mathrm{De}$ Camargo and Antunes ${ }^{25}$ in their study that was held in a specialized health care unit in São Paulo, Brazil, declared that $49.5 \%$ of children with $\mathrm{CP}$ had at least one untreated carious tooth. They have a poorer oral health condition than other children of similar age and geographic location, for both the primary and permanent dentition. On the contrary, an earlier study carried out in Denmark revealed that children with $\mathrm{CP}$, severe mental retardation (MR), and motor disturbances had a lower DMFS index and a higher caries-free rate than normal children, meaning that the dental health condition of children with $\mathrm{CP}$ and MR could be superior to that of children with $\mathrm{CP}$ but without MR, and even better than normal children, through the influence of preventive strategies as dental health education and fluoride application. ${ }^{26}$ In contrast, another survey conducted on $\mathrm{CP}$ children attending special schools in Leeds, England, disclosed that the caries status of children with $\mathrm{CP}$ was similar to that of normal children. ${ }^{18}$ However, they had less restorations, more extractions, minimal access to dental care, as well as poor oral hygiene and periodontal health, in addition to more dental plaque, gingivitis, and overjets. Additionally, this group of children demonstrated severe attrition of both primary and permanent dentitions. ${ }^{18}$

Moreover, recently in 2015, Sinha et $\mathrm{al}^{27}$ demonstrated that Indian children with $\mathrm{CP}$ had higher caries, poor oral hygiene, and class II malocclusion when compared with controls; this chiefly may be because of their compromised general health condition as well as lack of dental awareness.

The oral health status of children with $\mathrm{CP}$, considering gross motor skills and types of $\mathrm{CP}$, has not previously been reported in Egypt. As this group of children is considered an important segment of the population, the aim of this study was to assess the oral and dental health status among a group of Egyptian children with $\mathrm{CP}$ attending el-Shatby Hospital for Children in relation to gross motor skills and types of CP. In particular, the current study concerned about decayed, missing and filled permanent teeth (DMFT) index, decayed and filled primary teeth (dft) index, and oral hygiene status of $\mathrm{CP}$ children measured by simplified oral hygiene index (OHI-S) as well as modified gingival index (MGI). The outcomes achieved would serve as baseline data for planning oral health preventive programs aimed at enhancing the dental care in the future as well as improving the oral health of this group of children.

\section{MATERIALS AND METHODS}

This cross-sectional study was conducted at el-Shatby Hospital for Children, Alexandria Faculty of Medicine, Alexandria University, Egypt. Alexandria University Children's Hospital is the main pediatric hospital in the North Coast Region. It serves as a tertiary referral center for four governorates: Alexandria, Beheira, Matrouh, and Kafr El Sheikh. It has about 264 inpatient beds with more than 70,800 acute admissions a year. The study sample consisted of $10 \%$ of $\mathrm{CP}$ children attending the outpatient specialty clinics selected randomly in each visit to the clinics between May and October 2015, after getting prior permission from the relevant authorities and the approval of the Dental Ethical Committee for the study protocol that was performed in accordance with the World Medical Association Declaration of Helsinki principles for Medical Research involving human subjects to maintain the ethics. ${ }^{28}$ The nature of the study was clarified to the parents/caregivers through an informed consent; in case of agreement, they were requested to sign the written consent.

Children's medical records were reviewed for demographic and clinical data, including age, gender, $\mathrm{CP}$ 
type, and Gross Motor Function Classification System (GMFCS); a proforma was filled including these data. The participating children were classified as spastic, dyskinetic, ataxic, or mixed type of CP child according to Swedish classification system. ${ }^{29}$ Additionally, the children with CP were classified according to GMFCS. ${ }^{30}$ Exclusion criteria were: Associated disorders, such as MR, and children aged below 3 years and above 12 years.

After the exclusion of nonconformity cases, the sample size consisted of a total of $62 \mathrm{CP}$ children who were subjected to oral examination by one examiner. Children were examined in the outpatient clinic for both hard and soft dental tissues, lying on a bed under the natural light using sterile plane mouth mirror following the criteria recommended by the World Health Organization (WHO) 2013. ${ }^{31}$ All examinations were visual, and no probes were used due to the difficult behavior of the $\mathrm{CP}$ children, and to ensure the safety of the child and examiner during the examination process.

Dental health status of the participants was measured by using DMFT and dft indices according to WHO, Oral Health Assessment Form for Children, 2013. ${ }^{31}$ Also, clinical measurement of tooth wear was detected by using the Simplified scoring criteria for Tooth Wearing Index, 2004. ${ }^{32}$ According to the index, the teeth were assessed as followed: 0 , no wear in dentin; 1 , dentin just visible (including cupping) or dentin exposed less than one-third of surface; 2 , dentin exposure greater than one-third of surface; and 3 , exposure of pulp or secondary dentin. Additionally, the presence or absence of maxillofacial defects as cleft lip/ palate, as well as bruxism was identified and the eruption status of the contributing children was observed in the form of normal or delayed eruption. The children were checked also for the presence of other oral conditions. Drooling control was assessed by applying the scale developed by Thomas-Stonell and Greenberg, ${ }^{33}$ Drooling Frequency and Severity Scale (DFSS). Determination of drooling severity and frequency was based on the method of observation regulated in appointments with the parents/caregivers and concerned physiotherapists. Drooling status of the CP children was specified numerically by applying the DFSS. ${ }^{33}$ With regard to the scale, drooling severity was evaluated as followed: 1, dry (no drooling); 2, mild (humid lips only); 3, moderate (humid lips and chin); 4, severe (clothing begins to be affected); and 5, profuse (clothes, hands, and objects are wet). Drooling frequency was assessed as followed: 1, no drooling; 2 , occasionally drools (not every day); 3 , frequently drools (part of the day); and 4, constantly drools.

Oral hygiene status of the participating children was evaluated by means of OHI-S for ages 4 to 6 and 7 to 10 (deciduous and mixed dentition), ${ }^{34}$ with slight modification in the age range. For oral hygiene assessment, children were divided into two groups: (1) 4 to 6 years and below; (2) 7 to 10 years and above. The criteria described by Green and Vermillion, ${ }^{35}$ were selected. Calculus was excluded. For the ages 4 to 6 years and below, the labial surfaces of the 54,61, 82 and the lingual surface of 75 were selected, and for the mixed dentition (7-10 years and above) the labial surface of 26 and the lingual surface of 46 were added. For interpretation of the findings, the OHI-S (simplified debris index) was scored as follows: 0.0 to 0.6 = good oral hygiene; 0.7 to $1.8=$ fair oral hygiene; 1.9 to $3.0=$ poor oral hygiene. ${ }^{34}$ Finally, the $\mathrm{MGI}^{36}$ was used to assess the prevalence and severity of gingivitis among the participating children. This index is strictly based on noninvasive approach, i.e., visual examination only without any probing. To achieve MGI, labial and lingual surfaces of the gingival margins and the interdental papilla of all erupted teeth were examined and scored as follows: 0 , normal (absence of inflammation); 1, mild inflammation (slight change in color, little change in texture) of any portion of the gingival unit; 2 , mild inflammation of the entire gingival unit; 3 , moderate inflammation (moderate glazing, redness, edema, and/or hypertrophy) of the gingival unit; and 4, severe inflammation (marked redness and edema/hypertrophy, spontaneous bleeding, or ulceration) of the gingival unit. For interpretation of the outcomes, a modification was applied to the method of interpretation of gingival index (GI), ${ }^{37}$ and the MGI was scored as follows: 0.1 to $1.0=$ mild inflammation of any portion of the gingiva; 1.1 to $2.0=$ mild inflammation of the entire gingiva; 2.1 to $3.0=$ moderate inflammation, and 3.1 to $4.0=$ severe inflammation.

To make sure that intraexaminer reliability is achieved, a blind reexamination of $6 \mathrm{CP}$ children was performed (10\% of the sample) and the Cohen's kappa score ${ }^{38}$ was found to be 0.91 .

\section{Statistical Analysis}

Statistical analysis was conducted using the Statistical Package for the Social Sciences program (version 19.0 for windows, SPSS Inc., Chicago, USA). All statistical analyses were carried out at a significance level less than 0.05 and 0.01 . The data were analyzed for frequency distributions. Data were subjected to descriptive statistics like frequencies, percentages, and cross-tabulation. Pearson's correlation coefficient was used to investigate associations between the studied variables. Lastly, linear regression analysis was conducted to figure out which factors have the main effect on the studied condition.

\section{RESULTS}

The study included 62 children suffering from CP, $61.3 \%$ boys and $38.7 \%$ girls, with an average age of 6.5 years 
(standard deviation $[\mathrm{SD}] \pm 2.6$ years) and the age range was 3 to 12 years, with $45.2 \%$ of the participants in the age category "less than 6 years old," $29.0 \%$ in the age group "6 to less than 9 years old" and $28.8 \%$ "9 years and more."

Table 1 reveals the types of $\mathrm{CP}$, motor milestone, and the GMFCS among the studied group. It was found that the majority of the children $(83.9 \%)$ were suffering from spastic quadriplegia CP, while $6.5 \%$ of the studied children were suffering from ataxic $\mathrm{CP}$ and the same percentage of children were suffering from spastic diplegia. Finally, only $3.2 \%$ of the studied children had right hemiplegia. About $42.0 \%$ of the studied subjects were sit-supported, followed by $16.0 \%$ who were stand supported. On the contrary, more than one-fifth (22.6\%) of the studied subjects had no neck support, and less than $10 \%$ were sitting alone as well as walking alone. Concerning the GMFCS for CP, it was found that $32.3 \%$ of the studied group had self-mobility with limitations or may use powered mobility (level IV), followed by $29.0 \%$ who were transported in a manual wheelchair (level V) and $19.4 \%$ of the children walked with limitations (level II).

Regarding the maxillofacial defects as well as oral and dental problems of the participants, all the studied subjects had no maxillofacial defects, whereas only $19.4 \%$ of the children had bruxism. Concerning the tooth wearing index, the majority of children $(71.0 \%)$ had normal teeth, whereas just $14.5 \%$ had dentin exposure greater
Table 1: Types of CP, motor milestone, and GMFCS among the studied group $(n=62)$

\begin{tabular}{llll}
\hline & Variable & Frequency & Percent \\
\hline Diagnosis & Ataxic & 4 & 6.5 \\
& Spastic quadriplegia & 52 & 83.9 \\
& Spastic diplegia & 4 & 6.5 \\
& Spastic hemiplegia (Rt) & 2 & 3.2 \\
Motor milestone & Sit-supported & 26 & 41.9 \\
& Stand-supported & 10 & 16.1 \\
& No neck support & 14 & 22.6 \\
& Sit alone & 6 & 9.7 \\
GMFCS & Walk alone & 6 & 9.7 \\
& Level I & 2 & 3.2 \\
& Level II & 12 & 19.4 \\
& Level III & 10 & 16.1 \\
& Level IV & 20 & 32.3 \\
& Level V & 18 & 29.0 \\
\hline
\end{tabular}

than one-third of the surface. With regard to the other oral conditions, $6.5 \%$ of the children had open bite and developed class II, while $8.1 \%$ had heavy food accumulation, $4.8 \%$ showed history of oral ulcers, and $6.5 \%$ were experiencing malocclusion. Furthermore, only $32.3 \%$ of the participating children were suffering from delayed eruption. Moreover, merely 33.9\% of the studied group had no drooling of saliva, with $22.6 \%$ had frequent and severe drooling and $19.4 \%$ were suffering from constant profuse drooling of saliva (Table 2).

Table 2: Maxillofacial defects as well as oral and dental problems of the studied group $(n=62)$

\begin{tabular}{|c|c|c|c|}
\hline \multicolumn{2}{|l|}{ Variable } & Frequency & Percent \\
\hline \multirow[t]{2}{*}{ Maxillofacial defects } & Yes & 0 & 0 \\
\hline & No & 62 & 100 \\
\hline \multirow[t]{2}{*}{ Bruxism } & Yes & 12 & 19.4 \\
\hline & No & 50 & 80.6 \\
\hline \multirow[t]{5}{*}{ Tooth wearing index } & Normal tooth & 44 & 71 \\
\hline & No wear into dentin & 3 & 4.8 \\
\hline & $\begin{array}{l}\text { Dentin just visible (including cupping) or dentin exposed for less } \\
\text { than one-third of surface }\end{array}$ & 4 & 6.5 \\
\hline & Dentin exposure greater than one-third of surface & 9 & 14.5 \\
\hline & Exposure of pulp or secondary dentin & 2 & 3.2 \\
\hline \multirow[t]{4}{*}{ Other oral conditions } & Open bite and developing class II & 4 & 6.5 \\
\hline & Heavy food accumulation & 5 & 8.1 \\
\hline & History of oral ulcers & 3 & 4.8 \\
\hline & Malocclusion & 4 & 6.5 \\
\hline \multirow[t]{2}{*}{ Eruption status } & Normal eruption & 42 & 67.7 \\
\hline & Delayed eruption & 20 & 32.3 \\
\hline \multirow[t]{10}{*}{ Drooling of saliva } & Drooling severity & & \\
\hline & Dry, no drooling & 21 & 33.9 \\
\hline & Mild: Humid lips only & 4 & 6.5 \\
\hline & Moderate: Humid lips and chin & 11 & 17.7 \\
\hline & Severe: Clothing begins to be affected & 14 & 22.6 \\
\hline & $\begin{array}{l}\text { Profuse: Clothes, hands, and objects are wet } \\
\text { Drooling frequency }\end{array}$ & 12 & 19.4 \\
\hline & No drooling & 21 & 33.9 \\
\hline & Occasionally drools & 15 & 24.2 \\
\hline & Frequently drools & 14 & 22.6 \\
\hline & Constantly drools & 12 & 19.4 \\
\hline
\end{tabular}


Assessment of Oral and Dental Health Status in Children with Cerebral Palsy

Table 3: Dental and oral hygiene status of the studied group $(n=62)$

\begin{tabular}{|c|c|c|c|c|}
\hline Variable & & & Frequency & Percent \\
\hline \multirow[t]{10}{*}{ DMFT index } & Caries prevalence & Children who are caries free & 28 & 45.2 \\
\hline & & Children with carious teeth & 34 & 54.8 \\
\hline & Caries distribution* & Upper anterior carious teeth & 18 & 29.0 \\
\hline & & Upper posterior carious teeth & 25 & 40.3 \\
\hline & & Lower anterior carious teeth & 8 & 12.9 \\
\hline & & Lower posterior carious teeth & 29 & 46.8 \\
\hline & \multicolumn{2}{|c|}{ Mean $( \pm S D)$} & \multicolumn{2}{|c|}{$4.18( \pm 5.60)$} \\
\hline & \multicolumn{2}{|c|}{ Minimum } & \multicolumn{2}{|l|}{0} \\
\hline & \multicolumn{2}{|c|}{ Maximum } & \multicolumn{2}{|l|}{22} \\
\hline & & Age frequ & $y(\%)$ & Total frequency \\
\hline \multirow[t]{8}{*}{$\mathrm{OHI}-\mathrm{S}$} & Score & $4-6$ years and below & $7-10$ years and above & (\%) within age \\
\hline & Good & $19(52.8)$ & $5(19.2)$ & $24(38.7)$ \\
\hline & Fair & $2(5.6)$ & $3(11.5)$ & $5(8.1)$ \\
\hline & Poor & $15(41.7)$ & $18(69.2)$ & $33(53.2)$ \\
\hline & \multicolumn{2}{|c|}{ Mean $( \pm S D)$} & \multicolumn{2}{|c|}{$1.60( \pm 1.10)$} \\
\hline & \multicolumn{2}{|c|}{ Minimum } & \multicolumn{2}{|c|}{0} \\
\hline & \multicolumn{2}{|c|}{ Maximum } & \multicolumn{2}{|l|}{3} \\
\hline & & Age frequ & $y(\%)$ & Total frequency \\
\hline \multirow[t]{9}{*}{ MGI } & Score & $4-6$ years and below & $7-10$ years and above & (\%) within age \\
\hline & Normal & $6(16.7)$ & $3(11.5)$ & $9(14.5)$ \\
\hline & Mild inflammation & $4(11.1)$ & $0(0.0)$ & $4(6.5)$ \\
\hline & $\begin{array}{l}\text { Mild inflammation of the entire } \\
\text { gingival unit }\end{array}$ & $9(25.0)$ & $2(7.7)$ & $11(17.7)$ \\
\hline & Moderate inflammation & $5(13.9)$ & $6(23.1)$ & $11(17.7)$ \\
\hline & Severe inflammation & $12(33.3)$ & $15(57.7)$ & $27(43.6)$ \\
\hline & \multicolumn{2}{|c|}{ Mean $( \pm S D)$} & \multicolumn{2}{|c|}{$1.64( \pm 1.05)$} \\
\hline & \multicolumn{2}{|c|}{ Minimum } & \multicolumn{2}{|c|}{0} \\
\hline & \multicolumn{2}{|c|}{ Maximum } & \multicolumn{2}{|l|}{3} \\
\hline
\end{tabular}

*Percent of affected teeth

Table 3 represents the distribution of dental and oral hygiene status of the studied subjects. It was found that caries prevalence constituted $54.8 \%$ among the participating children, with dft index mean $( \pm \mathrm{SD})=2.77( \pm 4.59)$ and DMFT index mean $( \pm \mathrm{SD})=1.43( \pm 3.12)$. The most affected teeth by caries were the lower posteriors $(85.3 \%)$ followed by the upper posterior teeth $(73.5 \%)$, then the upper anterior teeth $(52.9 \%)$, and the least affected teeth were the lower anterior $(23.5 \%)$. With regard to the oral hygiene status of the participants, the majority of children $(53.2 \%)$ had poor oral hygiene represented through the OHI-S with a mean index $( \pm \mathrm{SD})=1.60( \pm 1.10)$ in which $69.2 \%$ of older children in the age of 7 to 10 years and above had poor oral hygiene, and severe gingival inflammation (43.6\%) represented by the MGI with a mean index $( \pm \mathrm{SD})=1.64( \pm 1.05)$, where $57.7 \%$ of children 7 to 10 years and above had severe gingivitis.

Table 4 represents Pearson's correlation coefficient between different studied variables. A strong correlation was detected between the diagnosis of $\mathrm{CP}$ and the other oral conditions, eruption status, $\mathrm{dft}$, and oral hygiene status (OHI-S). Moreover, a correlation was found between the motor milestone and the other oral conditions that affect this group of children as well as dft index. Finally, a strong correlation was registered between the GMFCS for CP and drooling of saliva, tooth wearing index, DMFT index, and the oral hygiene status in the form of OHI-S as well as the MGI.

Table 5 portrays the effect of each independent variable in relation to $\mathrm{CP}$ assessed by caries index for deciduous teeth (dft). Out of the ten variables studied, only one variable was statistically associated with caries index for deciduous teeth $(\mathrm{dft})$. The first best predictor variable for dft index was "motor milestone," where those children who were sit-supported had no neck support and those who were stand-supported were suffering from dental caries (dft) 21.6 times more than those children who were sitting and walking alone.

Additionally, Table 6 illustrates the effect of each independent variable in relation to $\mathrm{CP}$ assessed by caries index for permanent teeth (DMFT). It was detected that out of 10 variables studied, again only one variable was statistically associated with the occurrence of dental caries. The GMFCS was found to be the first best predictor variable for DMFT index, where those children who had self-mobility with limitations or may use powered 


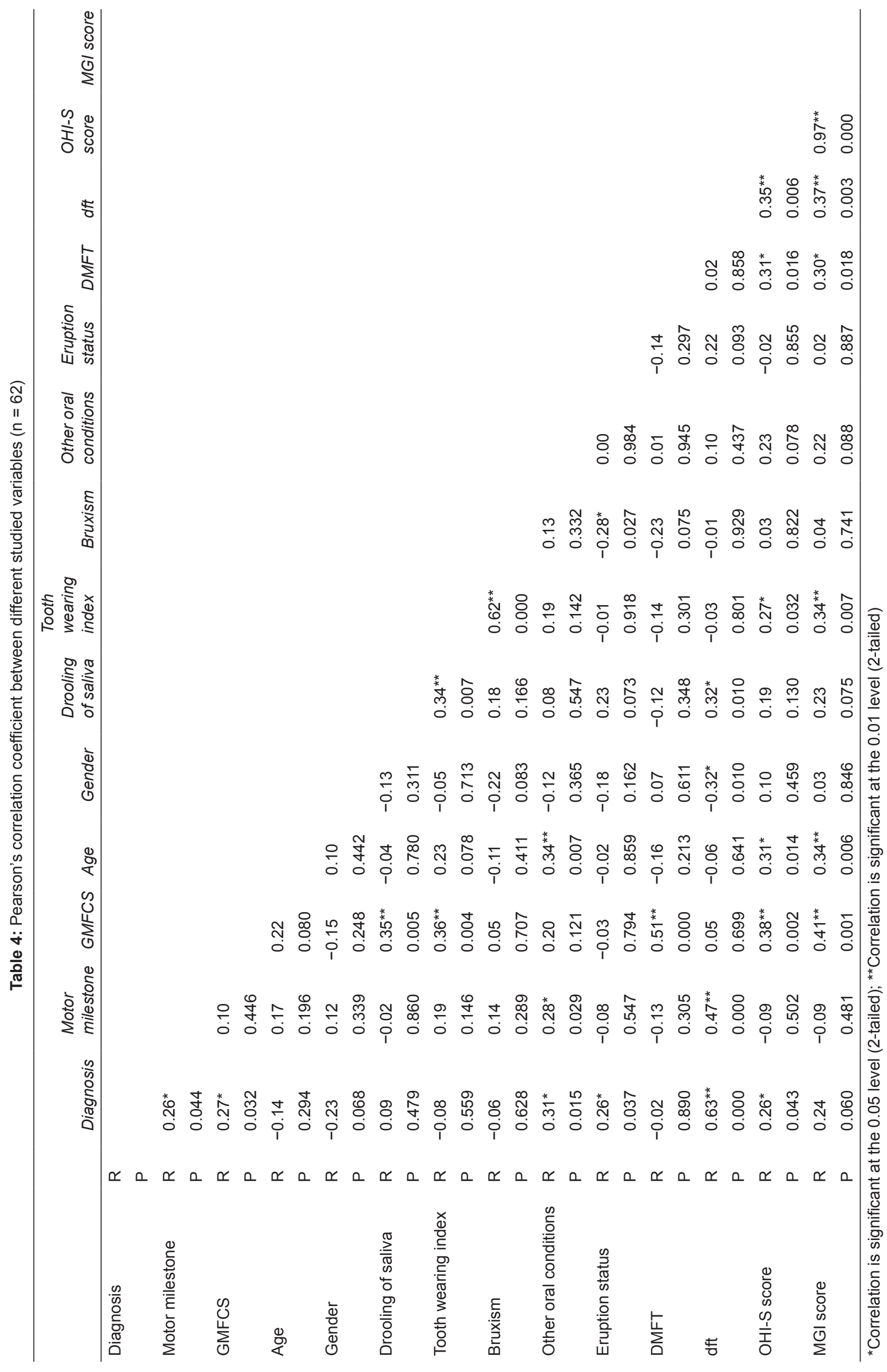


Assessment of Oral and Dental Health Status in Children with Cerebral Palsy

Table 5: Significant variables related to CP assessed by dft index based on linear regression analysis

\begin{tabular}{|c|c|c|c|c|c|c|c|}
\hline \multirow[b]{2}{*}{ Model } & \multirow[b]{2}{*}{ Variables } & \multirow{2}{*}{$\begin{array}{l}\begin{array}{l}\text { Unstandardized } \\
\text { coefficients }\end{array} \\
B \\
\end{array}$} & \multirow{2}{*}{$\begin{array}{l}\text { Standardized } \\
\text { coefficients } \\
\text { Beta }\end{array}$} & \multirow[b]{2}{*}{$R^{2}$} & \multirow[b]{2}{*}{$R^{2}$ change } & \multirow[b]{2}{*}{$t$} & \multirow[b]{2}{*}{$p$-value } \\
\hline & & & & & & & \\
\hline \multirow[t]{2}{*}{1} & (Constant) & 3.037 & & 0.216 & 0.216 & 4.005 & 0.000 \\
\hline & Motor milestone & -0.828 & -0.465 & & & -2.676 & 0.013 \\
\hline
\end{tabular}

Dependent variable: Dft

Table 6: Significant variables related to CP assessed by DMFT index based on linear regression analysis

\begin{tabular}{|c|c|c|c|c|c|c|c|}
\hline \multirow[b]{2}{*}{ Model } & \multirow[b]{2}{*}{ Variables } & \multirow{2}{*}{$\begin{array}{l}\text { Unstandardized } \\
\text { coefficients } \\
B\end{array}$} & \multirow{2}{*}{$\begin{array}{l}\begin{array}{l}\text { Standardized } \\
\text { coefficients }\end{array} \\
\text { Beta } \\
\end{array}$} & \multirow[b]{2}{*}{$R^{2}$} & \multirow[b]{2}{*}{$R^{2}$ change } & \multirow[b]{2}{*}{$t$} & \multirow[b]{2}{*}{$p$-value } \\
\hline & & & & & & & \\
\hline \multirow[t]{2}{*}{1} & (Constant) & 7.517 & & 0.263 & 0.263 & 4.724 & 0.000 \\
\hline & GMFCS & -0.192 & -0.513 & & & -3.275 & 0.003 \\
\hline
\end{tabular}

Dependent variable: DMFT

Table 7: Significant variables related to $\mathrm{CP}$ assessed by $\mathrm{OHI}-\mathrm{S}$ based on linear regression analysis

\begin{tabular}{|c|c|c|c|c|c|c|c|}
\hline \multirow[b]{2}{*}{ Model } & \multirow[b]{2}{*}{ Variables } & \multirow{2}{*}{$\begin{array}{l}\text { Unstandardized } \\
\text { coefficients } \\
B\end{array}$} & \multirow{2}{*}{$\begin{array}{l}\text { Standardized } \\
\text { coefficients } \\
\text { Beta } \\
\end{array}$} & \multirow[b]{2}{*}{$R^{2}$} & \multirow[b]{2}{*}{$R^{2}$ change } & \multirow[b]{2}{*}{$t$} & \multirow[b]{2}{*}{$p$-value } \\
\hline & & & & & & & \\
\hline \multirow[t]{2}{*}{1} & (Constant) & 0.665 & & 0.147 & 0.147 & 2.088 & 0.041 \\
\hline & GMFCS & 0.045 & 0.382 & & & 3.221 & 0.002 \\
\hline
\end{tabular}

Dependent variable: OHI-S

Table 8: Significant variables related to $\mathrm{CP}$ assessed by modified gingival index based on linear regression analysis

\begin{tabular}{|c|c|c|c|c|c|c|c|}
\hline \multirow[b]{2}{*}{ Model } & \multirow[b]{2}{*}{ Variables } & \multirow{2}{*}{$\begin{array}{l}\text { Unstandardized } \\
\text { coefficients } \\
\text { B } \\
\end{array}$} & \multirow{2}{*}{$\begin{array}{l}\text { Standardized } \\
\text { coefficients } \\
\text { Beta } \\
\end{array}$} & \multirow[b]{2}{*}{$R^{2}$} & \multirow[b]{2}{*}{$R^{2}$ change } & \multirow[b]{2}{*}{$t$} & \multirow[b]{2}{*}{$p$-value } \\
\hline & & & & & & & \\
\hline \multirow[t]{2}{*}{1} & (Constant) & 0.680 & & 0.170 & 0.170 & 2.267 & 0.027 \\
\hline & GMFCS & 0.046 & 0.413 & & & 3.510 & 0.001 \\
\hline \multirow[t]{3}{*}{2} & (Constant) & 0.132 & & & & 0.351 & 0.727 \\
\hline & GMFCS & 0.040 & 0.354 & 0.237 & 0.066 & 3.029 & 0.004 \\
\hline & Age & 0.106 & 0.264 & & & 2.265 & 0.027 \\
\hline
\end{tabular}

Dependent variable: MGI score

mobility (level IV), in addition to those who were transported in a manual wheelchair (level V) were 26.3 times prone to have dental caries (DMFT) than the rest of the children.

Furthermore, the effect of each independent variable in relation to $\mathrm{CP}$ was assessed by OHI-S. Out of the ten variables studied, only one variable was statistically associated with $\mathrm{OHI}-\mathrm{S}$. The first best predictor variable for oral hygiene was "GMFCS" as once again those children with levels IV and V were 14.7 times prone to suffer from bad oral hygiene more than children who had other levels of GMFCS (Table 7).

Finally, in Table 8, out of the 10 variables studied to detect the effect of each independent variable in relation to $\mathrm{CP}$ assessed by MGI, two variables were statistically associated with the manifestation of gingivitis. Again "GMFCS" was found to be the first best predictor variable for MGI as children with levels IV and V GMFCS were experiencing severe gingivitis 17.0 times more than chil- dren with levels I, II, and III GMFCS. "Age" constituted the second predictor variable, where older children with levels IV and V GMFCS were 6.6 times at higher risk of having severe gingivitis than younger children with I, II and III GMFCS levels.

\section{DISCUSSION}

Several studies associated with dental disease in CP have been done in the West but till now no studies have been done to evaluate dental problems in $\mathrm{CP}$ children in Egypt. The purpose of this study was to assess the oral and dental health status in a group of Egyptian children with $\mathrm{CP}$ in order to explore the oral health status and dental problems of this group of children.

In the current study, the percentage of boys with $\mathrm{CP}$ was greater than that of girls, which is in accord with the findings of earlier studies. ${ }^{24,25,39-41}$ Additionally, the present study found a high percentage of children with a high degree of impairment (83.9\% spastic quadriplegia), 
which is comparable to the results of a study carried out in Brazil by Guerreiro and Garcias. ${ }^{41}$ This profile of significant motor impairment potentially influenced the poor oral hygiene and severe gingival inflammation of the study sample as well as the presence of dental caries and drooling of saliva. The findings of this study are consistent with the outcome of an epidemiological survey carried out in 14 European countries, in which CP is more prevalent among males, with a superiority of the spastic form of the disease over the other types. ${ }^{42}$

Results of the current study revealed that no maxillofacial defects were found in the participating children; however, a low percentage of the children (19.4\%) were suffering from bruxism, which is the habitual grinding of teeth, i.e., a common occurrence in people with CP. These results are not in agreement with previous findings in which a high prevalence of bruxism was reported in persons who have $\mathrm{CP}^{43,44}$ Moreover, only $14.5 \%$ of children had tooth wear in the form of dentin exposure greater than one-third of the surface. This finding is lower than the findings of previous studies ${ }^{45-50}$ and is higher than that reported by Alhammad, ${ }^{51}$ where only $9.3 \%$ of the examined CP Saudi children living in Riyadh had tooth wear. However, comparison between studies should be explained with concern due to the lack of consistency in diagnostic criteria and age groups. Numerous studies have been performed to detect the prevalence of malocclusion in $\mathrm{CP}$ children but with different results. Findings of the current study revealed that only $6.5 \%$ of the sharing $\mathrm{CP}$ children had malocclusion. These results are lower than the outcomes of Chandna et $\mathrm{al}^{52}$ where they found that $70.58 \%$ of spastic $\mathrm{CP}$ children attending the outpatient clinic of the Department of Pedodontics and Preventive Dentistry, Christian Dental College, Ludhiana, India, had class II malocclusion. Additionally, Strodel ${ }^{53}$ discovered that spastic $\mathrm{CP}$ children had a greater propensity concerning class II malocclusion. The most important risk factors related with the severity of malocclusion in $\mathrm{CP}$ patients have been ascertained to be mouth breathing, lip incompetence, and long face..$^{54}$ In the present study, merely $6.5 \%$ of the children had anterior open bite; this result is lower than the findings of previous studies carried out by Giménez et $\mathrm{al}_{1}{ }^{55}$ and Morales Chávez et al ${ }^{56}$ in which they reported that $62 \%$ as well as $30 \%$ respectively, of the studied samples had anterior open bite. Additionally, this outcome is inconsistent with the findings of Carmagnani et $\mathrm{al}_{1}^{48}$ where they pointed that spastic patients presented with an increased incidence of open bite. The existence of malocclusion, anterior open bite, lip hypotonicity, and lingual incompetence complicates lip sealing and transport of the food bolus toward the posterior zone of the oral cavity; as a result, the commencement of swallowing is complicated. ${ }^{24,57,58}$ Tahmassebi and Luther ${ }^{58}$ have indicated a possible association between lip sealing and the presence of drooling in children with $\mathrm{CP}$ attending special schools in the county of Yorkshire. In the current work, two-thirds of the contributing $\mathrm{CP}$ children were suffering from drooling of saliva, with $22.6 \%$ having frequent and severe drooling and $19.4 \%$ experiencing constant profuse drooling of saliva. Moreover, $32.3 \%$ of the participating children had delayed eruption, which is coincident with the observations published by Rodrigues dos Santos et al, ${ }^{24}$ where they concluded that there was a strong tendency toward delayed eruption of the permanent molars in CP patients in the metropolitan area of Sao Paulo in Brazil.

In the present study, caries prevalence comprised $54.8 \%$ among the participating children, which is higher than the findings of Chu and $\mathrm{Lo}^{59}$ where they noted that a high proportion of decayed teeth ( $43 \%$ ) had been left untreated, indicating high caries involvement among Chinese students. Additionally, the caries experience in terms of mean dft/DMFT in this study was 2.77 and 1.43 respectively, which is higher than the findings of Chandna et $\mathrm{al}^{52}$ where they found that $\mathrm{dft} / \mathrm{DMFT}$ mean scores were 1.68 and 1.32 respectively. The current results are also higher than that of $\mathrm{Chu}$ and $\mathrm{Lo}^{59}$ where they reported that the DMFT score in their study was 1.2. The prevalence of high dft/DMFT investigated in CP children was referred to the lack of oral hygiene maintenance. Guaré and Ciamponi ${ }^{13}$ registered that Brazilian children with $\mathrm{CP}$ had greater prevalence of dental caries in the primary dentition than normal children. On the contrary, Du et al, ${ }^{50}$ in their study conducted in special child care centers in Hong Kong, revealed that children with and without $\mathrm{CP}$ had similar caries experiences. Moreover, previous studies declared that $\mathrm{CP}$ would lead to abnormal movements of the tongue and facial muscle ${ }^{25}$ together with low salivary flow, $\mathrm{pH}$, as well as buffering capacity, ${ }^{60}$ which might intensify the risk for dental caries. Results of the present study revealed that for younger participants, "motor milestone" affects the $\mathrm{dft}$ score, where those children who were sit-supported had no neck support and those who were stand-supported had dental caries 21.6 times more than those children who were sitting and walking alone. Decayed, missing, and filled permanent teeth score for older children was influenced by GMFCS, where those children who had selfmobility with limitations or may use powered mobility (level IV), in addition to those who were transported in a manual wheelchair (level V) were 26.3 times prone to have dental caries than the rest of the children. Poor oral hygiene is frequently mentioned as a problem influencing the oral health status of people with $C \mathrm{CP}^{14,16,61}$ Dos Santos and Nogueira ${ }^{14}$ revealed that the more severe the neurological damage, the more frequent is the incidence of the 
biting reflex and consequently, the higher is the risk of oral diseases in Brazilian children with spastic CP due to the difficulty to implement adequate oral hygiene. When oral hygiene was assessed, poor oral hygiene and severe gingival inflammation were a predominant finding in this study, where $53.2 \%$ of the contributing children had poor oral hygiene represented through the OHI-S with an average of 1.60 , and $43.6 \%$ of them had severe gingival inflammation represented by the MGI (mean = 1.64). These results are in accord with the findings of a previous study where $40 \%$ of the participants had poor oral hygiene. ${ }^{52}$ Also, Guaré and Ciamponi ${ }^{61}$ registered higher values of GI scores for Brazilian CP children with primary dentition in comparison to normal children. The oral hygiene status of the contributing children in the current study was affected by "GMFCS" as those children with levels IV and V were 14.7 times liable to have bad oral hygiene more than children who had other levels of GMFCS. Additionally, the gingival condition was influenced by "GMFCS" and "age" of the participants, as children with levels IV and V GMFCS were suffering from severe gingivitis 17.0 times more than children with levels I, II, and III GMFCS, and older children with levels IV and V GMFCS were 6.6 times at higher risk of experiencing severe gingivitis than younger children with I, II, and III GMFCS levels. A possible explanation for this may be that increased severity of the neurological damage in children with CP resulted in higher risk of oral diseases, ${ }^{13,14}$ and these individuals need to obtain efficient oral hygiene, but they are subjected to restricted oral care.

\section{CONCLUSION}

Based on the findings of the current study, the mainstream of participating children had spastic quadriplegia, less than half of them were sit-supported, and more than one-fifth of the participants had no neck support, with about one-third of the investigated group had self-mobility with limitations or may use powered mobility (level IV of GMFCS), followed by those who were transported in a manual wheelchair (level V). No maxillofacial defects were detected among children and less than one-fifth of them were suffering from bruxism, while a small number of children had tooth erosion in the form of dentin exposure greater than one-fifth of the surface. Regarding the other oral conditions, a minority of children had open bite and developed class II, heavy food accumulation, history of oral ulcers, and malocclusion. Additionally, less than one-third of the contributors were experiencing delayed eruption, and just about onethird of them had no drooling of saliva. On the contrary, more than half of the participants had dental caries, and the most affected teeth were the posteriors, lower followed by upper teeth, then the upper anterior teeth, and the least affected teeth were the lower anterior. The majority of children possessed poor oral hygiene and severe gingival inflammation. Moreover, children who were sit-supported had no neck support and those who were stand-supported were suffering from dental caries (dft) more than those children who were sitting and walking alone. Also, those children with levels IV and V GMFCS were prone to have dental caries (DMFT), susceptible to suffer from bad oral hygiene, and older children experiencing severe gingivitis more than younger ones with I, II, and III GMFCS levels.

\section{LIMITATIONS}

- Only children of el-Shatby Hospital were included in the study.

- Only children between 3 and 12 years were enrolled in the study.

\section{RECOMMENDATIONS}

- Increase the awareness of dental professionals concerning this group of children specifically, starting with dental students. This could be achieved through the enrollment of dental students in programs that permit them to visit those children in hospitals, schools, as well as the centers for children with special health care needs, so they can be acquainted with their environments, oral and dental health status, and treatment needs.

- Additionally, advanced training and long-term continuing education programs are recommended for dental professionals and ancillary staff to enhance their dental health awareness for this group of patients.

- Earlier preventive strategies in addition to professional and regular dental care should be incorporated within the framework of dedicated prophylactic and therapeutic programs for patients with $\mathrm{CP}$, as they are a high-risk group for dental caries and periodontal diseases.

- Oral health preventive and therapeutic programs should be offered specifically for preschool children to have early intervention before the deterioration of their oral and dental health.

- Health education program for caregivers and parents of these children regarding proper oral hygiene practice and nutrition in order to take care of their children.

- Further studies should be conducted incorporating children with CP who were not covered in the current work. Children could be recruited from schools, centers for children with special health care needs, clinics, as well as from their homes. 


\section{REFERENCES}

1. Dougherty NJ. A review of cerebral palsy for the oral health professional. Dent Clin North Am 2009 Apr;53(2):329-338, x.

2. Winter S, Autry A, Boyle C, Yeargin-Allsopp M. Trends in the prevalence of cerebral palsy in a population-based study. Pediatrics 2002 Dec;110(6):1220-1225.

3. Europe SoCPi. Prevalence and characteristics of children with cerebral palsy in Europe. Dev Med Child Neurol 2002 Sep;44(9):633-640.

4. Paneth N, Hong T, Korzeniewski S. The descriptive epidemiology of cerebral palsy. Clin Perinatol 2006 Jun;33(2):251-267.

5. Bhasin TK, Brocksen S, Avchen RN, Van Naarden Braun K. Prevalence of four developmental disabilities among children aged 8 years - Metropolitan Atlanta Developmental Disabilities Surveillance Program, 1996 and 2000. MMWR Surveill Summ 2006 Jan;55(1):1-9.

6. Yeargin-Allsopp M, Van Naarden Braun K, Doernberg NS, Benedict RE, Kirby RS, Durkin MS. Prevalence of cerebral palsy in 8-year-old children in three areas of the United States in 2002: a multisite collaboration. Pediatrics 2008 Mar;121(3):547-554.

7. Arneson CL, Durkin MS, Benedict RE, Kirby RS, YearginAllsopp M, Van Naarden Braun K, Doernberg NS. Prevalence of cerebral palsy: autism and developmental disabilities monitoring network, three sites, United States, 2004. Disabil Health J 2009 Jan;2(1):45-48.

8. Jones MW, Morgan E, Shelton JE. Primary care of the child with cerebral palsy: a review of systems (part II). J Pediatr Health Care 2007 Jul-Aug;21(4):226-237.

9. Sehrawat N, Marwaha M, Bansal K, Chopra R. Cerebral palsy: a dental update. Int J Clin Pediatr Dent 2014 May-Aug;7(2): 109-118.

10. Ingram, TTS. A historical view of the definition and classification of the cerebral palsies. In: Stanley F, Alberman A, editors. The epidemiology of the cerebral palsies. Philadelphia: JB Lippincott; 1984. p. 1-12.

11. Bleck, EE. Orthopaedic management in cerebral palsy. Philadelphia: JB Lippincott; 1987.

12. Koman LA, Smith BP, Shilt JS. Cerebral palsy. Lancet 2004 May;363(9421):1619-1631.

13. Guaré Rde O, Ciamponi AL. Dental caries prevalence in the primary dentition of cerebral-palsied children. J Clin Pediatr Dent 2003 Spring;27(3):287-292.

14. Dos Santos MT, Nogueira ML. Infantile reflexes and their effects on dental caries and oral hygiene in cerebral palsy individuals. J Oral Rehabil 2005 Dec;32(12):880-885.

15. Reddihough DS, Collins KJ. The epidemiology and causes of cerebral palsy. Aust J Physiother 2003 Feb;49(1):7-12.

16. Subasi F, Mumcu G, Koksal L, Cimilli H, Bitlis D. Factors affecting oral health habits among children with cerebral palsy: pilot study. Pediatr Int 2007 Dec;49(6):853-857.

17. Shaw L, Maclaurin ET, Foster TD. Dental study of handicapped children attending special schools in Birmingham, UK. Community Dent Oral Epidemiol 1986 Feb;14(1):24-27.

18. Pope JE, Curzon ME. The dental status of cerebral palsied children. Pediatr Dent 1991 May-Jun;13(3):156-162.

19. Evans DJ, Greening S, French AD. A study of the dental health of children and young adults attending special schools in South Glamorgan. Int J Paediatr Dent 1991 Apr;1(1):17-24.

20. Shapira J, Efrat J, Berkey D, Mann J. Dental health profile of a population with mental retardation in Israel. Spec Care Dentist 1998 Jul-Aug;18(4):149-155.
21. Desai M, Messer LB, Calache H. A study of the dental treatment needs of children with disabilities in Melbourne, Australia. Aust Dent J 2001 Mar;46(1):41-50.

22. Kozak R. Dental and periodontal status and treatment needs of institutionalized mentally retarded children from the province of West Pomerania. Ann Acad Med Stetin 2004;50(2):149-156.

23. Stevanovic $\mathrm{R}$, Jovicic $\mathrm{O}$. Oral health in children with cerebral palsy. Srp Arh Celok Lek 2004 Jul-Aug;132(7-8):214-218.

24. Rodrigues dos Santos MT, Masiero D, Novo NF, Simionato MR. Oral conditions in children with cerebral palsy. J Dent Child (Chic) 2003 Jan-Apr;70(1):40-46.

25. De Camargo MA, Antunes JL. Untreated dental caries in children with cerebral palsy in the Brazilian context. Int J Paediatr Dent 2008 Mar;18(2):131-138.

26. Nielsen LA. Caries among children with cerebral palsy: relation to CP - diagnosis, mental and motor handicap. ASDC J Dent Child 1990 Jul-Aug;57(4):267-273.

27. Sinha N, Singh B, Chhabra KG, Patil S. Comparison of oral health status between children with cerebral palsy and normal children in India: a case-control study. J Indian Soc Periodontol 2015 Jan-Feb;19(1):78-82.

28. World Medical Association. World Medical Association Declaration of Helsinki: ethical principles for medical research involving human subjects. JAMA 2013 Nov;310(20):2191-2194.

29. Hagberg B, Sanner G, Steen M. The dysequilibrium syndrome in cerebral palsy. Clinical aspects and treatment. Acta Paediatr Scand Suppl 1972 Feb;226:1-63.

30. Palisano R, Rosenbaum P, Walter S, Russell D, Wood E, Galuppi B. Development and reliability of a system to classify gross motor function in children with cerebral palsy. Dev Med Child Neurol 1997 Apr;39(4):214-223.

31. World Health Organization. Oral health surveys: basic methods. 5th ed. Geneva: WHO; 2013.

32. Bardsley PF, Taylor S, Milosevic A. Epidemiological studies of tooth wear and dental erosion in 14-year-old children in North West England. Part 1: the relationship with water fluoridation and social deprivation. Br Dent J 2004 Oct;197(7):413416; discussion 399.

33. Thomas-Stonell N, Greenberg J. Three treatment approaches and clinical factors in the reduction of drooling. Dysphagia 1988 Jun;3(2):73-78.

34. Rodrigues CR, Ando T, Guimaraes LO. Simplified gingival index for ages 4 to 6 and 7 to 10. (deciduous and mixed dentition). Rev Odontol Univ Sao Paulo 1989 Jul-Sep;3(3):414-419.

35. Greene JC, Vermillion JR. The simplified oral hygiene index. J Am Dent Assoc 1964 Jan;68:7-13.

36. Lobene RR, Weatherford T, Ross NM, Lamm RA, Menaker L. A modified gingival index for use in clinical trials. Clin Prev Dent 1986 Jan-Feb;8(1):3-6.

37. Löe $H$. The gingival index, the plaque index and the retention index systems. J Periodontol 1967 Nov-Dec;38(6)(Suppl): 610-616.

38. Landis JR, Koch GG. The measurement of observer agreement for categorical data. Biometrics 1977 Mar;33(1):159-174.

39. Rodriguez Vázquez C, Garcillan R, Rioboo R, Bratos E. Prevalence of dental caries in an adult population with mental disabilities in Spain. Spec Care Dentist 2002 Mar-Apr;22(2):65-69.

40. Donnell DO, Sheiham A, Wai YK. Dental findings in 4-, 14-, and 25-to 35-year-old Hong Kong residents with mental and physical disabilities. Spec Care Dentist 2002 NovDec;22(6):231-234. 
41. Guerreiro PO, Garcias Gde L. Oral health conditions diagnostic in cerebral palsy individuals of Pelotas, Rio Grande do Sul State, Brazil. Cien Saude Colet 2009 Sep-Oct;14(5): 1939-1946.

42. Colver A. Benefits of a population register of children with cerebral palsy. Indian Pediatr 2003 Jul;40(7):639-644.

43. Lindqvist $B$, Heijbel J. Bruxism in children with brain damage. Acta Odontol Scand 1974 Jun;32(5):313-319.

44. Ortega AO, Guimaraes AS, Ciamponi AL, Marie SK. Frequency of parafunctional oral habits in patients with cerebral palsy. J Oral Rehabil 2007 May;34(5):323-328.

45. Shaw L, Weatherill S, Smith A. Tooth wear in children: an investigation of etiological factors in children with cerebral palsy and gastroesophageal reflux. ASDC J Dent Child 1998 Nov-Dec;65(6):484-486, 439.

46. Su JM, Tsamtsouris A, Laskou M. Gastroesophageal reflux in children with cerebral palsy and its relationship to erosion of primary and permanent teeth. J Mass Dent Soc 2003 Summer;52(2):20-24.

47. Schwartz S, Gisel EG, Clarke D, Haberfellner H. Association of occlusion with eating efficiency in children with cerebral palsy and moderate eating impairment. J Dent Child 2003 Jan-Apr;70(1):33-39.

48. Carmagnani FG, Goncalves GK, Corrêa MS, dos Santos MT. Occlusal characteristics in cerebral palsy patients. J Dent Child (Chic) 2007 Jan-Apr;74(1):41-45.

49. Gonçalves GK, Carmagnani FG, Corrêa MS, Duarte DA, Santos MT. Dental erosion in cerebral palsy patients. J Dent Child (Chic) 2008 May-Aug;75(2):117-120.

50. Du RY, McGrath C, Yiu CK, King NM. Oral health in preschool children with cerebral palsy: a case-control community-based study. Int J Paediatr Dent 2010 Sep;20(5): 330-335.
51. Alhammad NS. Tooth wear, enamel hypoplasia and traumatic dental injuries among cerebral palsy children of Riyadh city. King Saud Univ J Dent Sci 2011 Jul;2(1-2):1-5.

52. Chandna P, Adlakha VK, Joshi JL. Oral status of a group of cerebral palsy children. J Dent Oral Hyg 2011 Feb;3(2):18-21.

53. Strodel BJ. The effects of spastic cerebral palsy on occlusion. ASDC J Dent Child 1987 Jul-Aug;54(4):255-260.

54. Miamoto CB, Ramos-Jorge ML, Pereira LJ,PaivaSM, PordeusIA, Marques LS. Severity of malocclusion in patients with cerebral palsy: determinant factors. Am J Orthod Dentofacial Orthop 2010 Oct;138(4):394.e1-394.e5, discussion 94-95.

55. Giménez MJ, López Jiménez J, Boj Quesada JR. Estudio de las maloclusiones en una población con parálisis cerebral. Rev Iberoam Ortod 2002 Jun;21(1):33-41.

56. Morales Chávez MC, Nualart Grollmus ZC, Silvestre-Donat FJ. Clinical prevalence of drooling in infant cerebral palsy. Med Oral Patol Oral Cir Bucal 2008 Jan;13(1):E22-E26.

57. Sochaniwskyj AE, Koheil RM, Bablich K, Milner M, Kenny DJ. Oral motor functioning, frequency of swallowing and drooling in normal children and in children with cerebral palsy. Arch Phys Med Rehabil 1986 Dec;67(12):866-874.

58. Tahmassebi JF, Luther F. Relationship between lip position and drooling in children with cerebral palsy. Euro J Paediatr Dent 2004 Sep;5(3):151-156.

59. Chu $\mathrm{CH}$, Lo EC. Oral health status of chinese teenagers with cerebral palsy. Community Dent Health 2010 Dec;27(4):222-226.

60. Santos MT, Guaré R, Leite M, Ferreira MC, Nicolau J. Does the neuromotor abnormality type affect the salivary parameters in individuals with cerebral palsy? J Oral Pathol Med 2010 Nov;39(10):770-774.

61. Guaré Rde O, Ciampioni AL. Prevalence of periodontal disease in the primary dentition of children with cerebral palsy. J Dent Child (Chic) 2004 Jan-Apr;71(1):27-32. 